approach. In the second part these questions are repeated, followed by more detailed sub-questions. No answers are supplied although the prognosis and management are hinted at in some of the subquestions.

The contents cover a wide area ranging from the 'Balint' type questions 'Why has this patient really come?' or 'Is the 'patient' always the one presenting to you?" to cases of patients with problems such as chest pain, tiredness or urinary tract symptoms.

Some of the histories are fascinating and present in a readable form a wide range of primary care problems. They also highlight some of the differences in doctor-patient relationships in the United Kingdom, Australia and Canada, and the degree of intervention expected of family practitioners in these countries.

This book is of value for general practitioner teachers of vocational trainees, and would be a useful addition to a library of a Teaching Practice. It can be used as a resource for small group seminars, discussing topics such as 'tiredness', 'the dying patient' or 'family crises'. The short case histories are not a substitute for the discussion of patients seen by the trainees or students in their general practices. These must continue to remain the most important material for any teaching programme in the same way that video tapes of consultations involving the trainee are more useful, though often less technically satisfactory than video cassettes provided by organisations outside the practice.

Michael Modell General Practice Unit, University College London, London WCIE 6JJ.

The New Good Birth Guide. How to Research and Plan the Kind of Birth to suit you and your Partner

By Sheila Kitzinger. Pp. 443, illustrated. Penguin Books, London, 1983. £3.95.

The first third of this new edition of the Good Birth Guide is an excellent summary of the techniques which may be used in what Sheila Kitzinger aptly calls 'the medical way of birth' and this first section is followed by three devoted to new ways of birth, the postnatal period and how to plan for the birth that the couple want. Apart from a few statements (the shake test has surely been replaced by the sphingo-myelin lecithin ratio if this test is done at all these days, water intoxication in labour must be excessively rare) the reasons why these interventions need not be done routinely are expressed clearly and unemotionally, and sensible strategies for obtaining the type of birth that the couple feel is right are suggested.

Some obstetricians may feel that encouraging women to ask questions, to participate in decision making and to be assertive threatens their professional training and position but many will find much to think about in both this part of the book and the larger part devoted to a review of care in hospitals drawn from all parts of the United Kingdom (except Northern Ireland) and Eire.

The reports on the hospitals are compiled from at least 24 women and in many cases nursing officers or obstetricians. Two stars is the highest awarded but the majority of reports are not critical but attempt to give women an idea of the strengths and weaknesses of a particular unit so that they can exercise choice. As with the Good Food Guide, a change of personnel can make an appreciable difference to a place, and reports from 1979 may have little bearing on 1983. In the first edition I was struck by the phrase 'we learnt not to judge a hospital by its antenatal clinic', the majority of which seemed to be an endurance test for the pregnant woman, but in several places now appointment systems seem to be operating so maybe doctors, nurses and administrators have taken to heart the complaints of the consumers. Whilst many women will have no choice because of geographical constraints, knowing how to ask for what is wanted and what needs changing may encourage a consumer pressure group and for those of us working in the NHS, or outside, an outside appraisal prevents complacency. I am going to look at the toilets and bathrooms again in the postnatal ward not usually visited on ward-rounds! At $£ 3.95$ a useful addition to all hospital and postgraduate centre libraries.

W. D. SAVAGE

The London Hospital Medical College, London E1 1BB.

\section{Outline of Fractures}

By J. Crawford Adams. 8th edn. Pp. 324, illustrated. Churchill Livingstone, Edinburgh and London, 1983. £7.25.

It is pleasant to renew acquaintance with this old favourite which has probably been the most widely-read book on fractures for many years. It appears again in updated form combining the traditional teaching about fractures, their healing and their management with more modern views about the management of individual fractures.

The author sees the book as written primarily for medical students but also for postgraduates, orthopaedic nurses and physiotherapists. However, to the reader it may seem a little too large for undergraduate medical students with a style perhaps which discourages its being read from end to end. Its strength surely must lie as a reference book for junior doctors just starting on the management of fractures, casualty officers, senior house officers and the like. Every Accident and Emergency Department should have a book such as this to which quick reference can be made.

The description of fractures and their management is systematic and anatomical. This makes it easy to use for reference but somewhat repetitive to read. It is difficult to find fault with a book which covers well the sector towards which it was intended but perhaps an approach might be preferred in which management of the whole patient with a fracture rather than management of a fracture itself is described. For example, one might prefer the section on fractures in the region of the femoral neck to commence with a whole page on the problems of management of elderly patients with injuries. Apart from these minor criticisms one can but welcome the reappearance of this valuable textbook in revised form.

D. F. PATON

Whittington Hospital, London NI9 5NF.

\section{Recent Advances in Perinatal Medicine}

Edited by M. L. CHISwICK. Pp. 234, illustrated. Churchill Livingstone, Edinburgh, London, 1983. £15.00.

As acknowledged in Dr Chiswick's preface, obstetrics and neonatology can never be isolated but must always be viewed as a continuum of fetal and neonatal life. The authors of the various chapters are well-known specialists who, in general, not only present the current thinking and advances of their own areas, but also clearly review sufficient background knowledge to make unfamiliar areas fully comprehensible to the layman. The authors succeed in bringing together a large and wide ranging body of knowledge on each topic. Each chapter covers an area of considerable everyday importance. Pre-pregnancy planning is possibly the only area given short shrift with only maternal nutrition considered and this mainly from the context of pregnancy. Antepartum evaluation of fetal health, the diagnosis of fetal abnormality by ultrasound, and haemolytic disease of the newborn are considered in detail. The topics of premature rupture of membranes and care of the fetus in labour review intrapartum care and chapters on the outcome of birth asphyxia, the importance of temperature control, management of respiratory failure and hyaline membrane disease and artificial surfactant, are fully considered postnatal problems. The volume is completed surprisingly by an initial chapter on perinatal pathology. The book is aimed at a wide readership on both sides of the Atlantic. From the child health standpoint, it should certainly be read by all hospital paediatric staff who have any contact with the newborn. Similarly, concerned obstetricians of all grades will be interested from the obstetric standpoint.

NeIL MCINTOSH

St George's Hospital,

London SW17. 